\title{
Linking Protection with the Distribution of Grouper and Habitat Quality in Seychelles
}

\author{
Samantha J. Howlett, ${ }^{1}$ Richard Stafford, ${ }^{2}$ Matt Waller, ${ }^{3}$ \\ Sylvanna Antha, ${ }^{4}$ and Christophe Mason-Parker ${ }^{3}$ \\ ${ }^{1}$ Latvian State Forestry Research Institute "Silava”, Salaspils LV-2169, Latvia \\ ${ }^{2}$ Bournemouth University, Poole, Dorset BH12 5BB, UK \\ ${ }^{3}$ Global Vision International Seychelles, Victoria, Mahé, Seychelles \\ ${ }^{4}$ Seychelles National Parks Authority, Victoria, Mahé, Seychelles \\ Correspondence should be addressed to Samantha J. Howlett; samanthajhowlett@gmail.com
}

Received 1 April 2016; Accepted 27 July 2016

Academic Editor: Garth L. Fletcher

Copyright (C) 2016 Samantha J. Howlett et al. This is an open access article distributed under the Creative Commons Attribution License, which permits unrestricted use, distribution, and reproduction in any medium, provided the original work is properly cited.

\begin{abstract}
Marine protected areas can be designated for a number of reasons, but exactly how they provide benefits is only recently being understood. We assessed the effect of protection on the size and distribution of six common species of grouper in a coral reef ecosystem. Data on live coral cover, coral genus diversity, and coral colony structure type were also compared to give an indication of reef quality between sites. A significant interaction was found for Aethaloperca rogaa and Cephalopholis nigripinnis, indicating that protected areas held greater numbers of smaller and median sized fish of these species than unprotected areas. Similar but nonsignificant trends were found for Cephalopholis miniata and Cephalopholis argus. For Anyperodon leucogrammicus, MPAs held significantly more fish than unprotected sites, but as the increase was equal between size categories there was no interaction. The last species Epinephelus fasciatus, which was one of the smallest species, had no significant interaction, similar mean counts between protected and unprotected areas, and no obvious strong favouritism for particular sites with values indicating better reef quality, indicating intraspecies competition. The results of this study indicate that while the MPAs in this study are likely too small to benefit large groupers, the improvements to habitat quality have indirect benefits to groupers, especially at their earlier life stages.
\end{abstract}

\section{Introduction}

Marine protected areas (MPAs) have become an increasingly popular tool in marine management [1-4]. However, many MPAs are still fairly young, and the changes that may result from protecting areas are only recently becoming clear [511]. While the role of MPAs differs between locations and countries, MPAs are frequently used as an aspect of fisheries management to increase yields by facilitating recruitment to the population by providing refuge areas for individuals to reach sexual maturity and to increase the density of individuals in the surrounding area through either emigration of adults or larval dispersion [5, 12-15].

A number of studies have attempted to quantify exactly how MPAs benefit marine ecosystems and the economies associated with them. Many have found that marine reserves lead to an increase in the density/biomass of fish $[8,16-$ $18]$, and there are some studies that have found that MPAs typically hold a greater number of larger individuals $[9,17-$ 19], indicating that protection allows these fish to mature to greater ages than they would if they were exposed to fishing. However, studies such as Mateos-Molina et al. [10] have also found a higher abundance of small-sized species and early life stages suggesting greater recruitment.

Quantifying how MPAs can improve marine ecosystems can be challenging for a number of reasons. Many marine fauna are either migratory or wide ranging; therefore, as MPAs have no physical barriers, individuals can move outside and protection may have little effect. MPA size has been found to be an important factor in how effective it is for different 
families $[6,20,21]$ with many MPAs smaller than $10 \mathrm{~km}^{2}$ having limited protection from anthropogenic influences due to edge effects and are unlikely to cover the home ranges of most transient, predatory taxa. Many mobile species may be too big to benefit from small MPAs, with a study by Gell and Roberts [5] suggesting an optimum size of $16-24 \mathrm{~km}^{2}$ for their study on mobile estuarine fish.

Furthermore, the process of assessing MPA effectiveness can be complicated by a number of factors. Firstly, many studies are based on nonexperimental data; namely, they lack information on conditions prior to designation which allows for the establishment of a baseline or lack a control to measure the effects inside and outside following implementation [22]. Smith et al. [21] found spatial and temporal variances at a number of scales when assessing the effect of MPAs on exploited species. Another factor is that not all studies take into account responses of individual species, with many generalising at the family level.

The protection afforded by MPAs has been acknowledged to have wider effects than just increase the biomass of target species, with some MPAs being designated for ecosystem preservation and restoration. Research has shown that overfishing, especially of specific trophic and feeding groups, can upset ecosystem stability [11, 18, 23-26]; therefore, MPAs can help maintain the balance in marine communities, preventing cascading effects to the wider environment. Protection can even have positive feedbacks, allowing ecosystems to recover in deteriorated areas by allowing the recovery of trophic complexity [11, 18, 27, 28].

A wide range of studies over a number of decades have revealed that there are specific relationships with coral for a number of fish species [29-32] and that habitat complexity is an important factor for many reef species [33], with coral colonies that display complex branching structures, such as those within Acroporidae and Pocilloporidae, providing important refuge areas for juvenile or small reef dwelling fish $[31,34,35]$. These relationships allow for diverse ecosystems with complex interactions; therefore, prevention of overfishing and maintaining balance within these trophic levels is imperative to maintaining ecosystem health and stability. Reef predators are important in this way as they mediate populations of prey species [36], as well as encourage utilisation of various spaces [37]. Studies such as Dunne et al. [38] indicate that diverse communities should be more robust communities, since a more complex food web typically offers alternative prey when one prey species is lost. Therefore, areas that are in a more natural state can better withstand stochastic environmental events, such as El Niño [28, 39]. Furthermore, protecting ecosystem complexity can be used as a protective measure against climate change.

Groupers (family Serranidae) are a common top predator species associated with coral reefs and are a popular artisanal species throughout their geographic range. Groupers have a huge range in sizes, from the giant grouper which can reach up to more than $2.5 \mathrm{~m}$ long (Epinephelus lanceolatus [40]) to species such as the honeycomb grouper which typically only reaches around $30 \mathrm{~cm}$ (Epinephelus merra [41]).

Due to traits such as body and home range size, habitat requirements will vary significantly between species. High diversity within the Serranidae and the distribution of species-specific habitats indicates that protection may not have the same effect at the family level. Groupers can be easily susceptible to impacts from overfishing due to life history traits such as slow rates of maturation and aggregation spawning [42]. Most groupers are highly piscivorous and are one of the primary reef-resident predators; therefore, they play an important role in regulating prey populations.

The aim of our study was to explore a number of factors typically used to assess effectiveness of MPAs, namely, fish size and abundance, on the distribution of common species of grouper in a coral reef ecosystem. We also assessed factors such as live coral cover and coral diversity to see whether environmental factors varied between protected and unprotected sites. To address this we asked the following questions:

(i) Firstly, do MPAs result in more fish? Is there any difference in abundance of grouper between protected and unprotected sites?

(ii) Does size distribution vary between protected and unprotected sites? Is there an increase in density of larger fish within MPAs?

(iii) Do these factors affect different species of grouper equally?

(iv) Does protection affect environmental qualities? Does coral coverage and abundance of coral colony structure types vary between protected and unprotected areas?

(v) Are there any patterns between environmental qualities and the distribution of different grouper species?

\section{Materials and Methods}

2.1. Study Sites. The Seychelles is a group of islands within the Indian Ocean located to the North-East of Madagascar. It sits atop the Mascarene Plateau, and due to the relatively shallow waters, the area has a history of struggling with elevated sea temperatures during El Niño, most notably with the widespread coral bleaching in 1998 [43-45]. The data used in this study were collected by Global Vision International on behalf of the Seychelles National Parks Authority, the Governmental body in charge of monitoring and managing the National Parks. It is a subset of data collected for a project monitoring coral reef recovery in this area following the bleaching event.

A total of twenty-four sites were surveyed around the North-West coast of Mahé Island, Seychelles (Figure 1). Of these, six sites are located within the protected areas of Baie Ternay and Port Launay (four in BT and two in PL), with eighteen falling outside of MPAs. The Baie Ternay Marine National Park (BTMNP) and Port Launay Marine National Park (PMNP) were established in 1979 and with over 35 years of continuous protection can be considered fairly long standing [6]. In Seychelles, the primary objective of MNPs is to protect natural biodiversity, support environmental processes, and promote education and recreation [46]. MNPs are considered no-take areas and as such it is illegal to kill, 


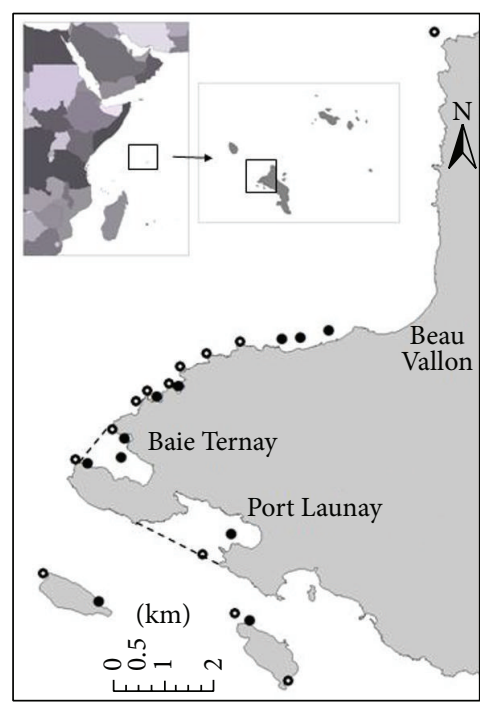

Substrate

- Carbonate

- Granitic

FIgURE 1: The location of Seychelles north of Madagascar, the location of Mahé within the Inner Islands, and the locations of both the marine parks and surveys along the North-West Mahé coastline.

capture, willfully injure, disturb, or destroy any animal within the park [47]. They are relatively small marine parks at only $0.8 \mathrm{~km}^{2}$ and $1.58 \mathrm{~km}^{2}$, respectively. Environmental conditions surrounding the two MPAs also vary. Baie Ternay is more remote and has restricted public access in comparison to Port Launay. Historically, both sites have been subjected to limited coastal development. As part of the National Youth Service, youth villages were built at both locations and operated during the 1980s and 1990s. A small waterfront restaurant was located at Cap Ternay between 1974 and 1981 and followed the construction of a sea wall towards the eastern end of the beach. Upon closure of the youth villages, a military dogtraining unit was established at Cap Ternay until it closed down in 2012. Today, the land adjacent to the BTMNP is uninhabited except for a coral reef monitoring programme run by Global Vision International (GVI) and the Seychelles National Parks Authority (SNPA). The coastal ecosystems in BTMNP remain relatively undisturbed, which is in contrast to the PLMNP, which sits adjacent to a large, high class hotel constructed on both the small peninsula and connecting land strip. Since the opening of the 277 room hotel in 2009, there has been an increase in anthropogenic activity within the PLMNP. The hotel has direct access to the main beach within the MNP and is frequented daily by a significant percentage of the resorts guests. To accommodate the increase in visitors, PLMNP now contains a number of moorings, which provide a permanent station for numerous watercrafts offering tourism services, while the hotel provides a portfolio of water-based activities (snorkeling, paddleboarding, diving, kayaking, etc.).

\subsection{Data Collection}

2.2.1. Groupers. Surveys were undertaken using SCUBA and consisted of a combination of stationary point counts and transect belts adapted from the methodology as set out in Engelhardt [48]. The stationary point counts surveyed a $7 \mathrm{~m}$ radius (survey area of $153.54 \mathrm{~m}^{2}$ ) for 7 minutes. The belt transects were $50 \mathrm{~m}$ with a $2.5 \mathrm{~m}$ corridor on either side of the tape, giving a belt survey area of $250 \mathrm{~m}^{2}$. Surveys were conducted to a maximum depth of $16 \mathrm{~m}$. A total of four belt transects and eight stationary point counts were completed on each site for every six-month period. As the primary aim of the project is to monitor coral and reef recovery, all sites have a visual landmark on the shore line from which surveys are evenly distributed. In this way, the same approximate area is resurveyed; however, no permanent transects were used. Surveys on sites were completed every 6 months from 2009 through to 2013. All groupers surveyed were placed into $10 \mathrm{~cm}$ size categories and all surveyors received training on land and in water prior to surveying to an accuracy standard of $95 \%$.

Data for each fish sighted in each size category at each location were totaled for each survey period (i.e., across all the transect belts and point counts in each six month survey period). Herein, this is referred to as the count of fish in the size category. As groupers have a high tendency to be territorial [49], the same fish could have been seen and counted on multiple dives. Given these counts are aggregated over half year time periods, it is more reasonable to assume that these counts are an indication of use of an area by fish of this size class. However, analysis of the number of each species of fish seen in a given size class at each time period indicates that the second most common value was 1 fish per size class over each half year sampling regime (the most common being zero). As such, repeated counting of the same individuals was not pronounced.

Survey locations were allocated to cover a range of carbonate and granitic substrates for protected and unprotected sites as these can harbour different reef environments. Due to the nature of site locations around the island, whether a site falls within an MPA or outside an MPA is likely to add variation. For example, sites situated outside of MPAs can range from those that fall close to the busy and developed town of Beau Vallon or to the North and North-West which can be deep and exposed. The two MPAs are both situated within bays; therefore, protected sites are likely to be shallower and less exposed. Because of this, site was nested within MPA and non-MPA to account for this variance.

The six most common species of grouper were used in this study, namely, the red mouth (Aethaloperca rogaa), slender (Anyperodon leucogrammicus), peacock (Cephalopholis argus), coral hind (Cephalopholis miniata), blacktip (Epinephelus fasciatus), and blackfin (Cephalopholis nigripinnis). Fishing pressure on groupers in the study area is believed to be fairly moderate. Coastal fishing is purely artisanal and multispecies, and while groupers are at risk of fishing, there is little selectivity specifically on these species in particular ([50], pers comm.). 
TABLE 1: Results of the mixed model analysis on the interaction between size category and MPA on the count of grouper species. Where no significant interaction term was found, the main effect of MPA was examined.

\begin{tabular}{|c|c|c|c|c|}
\hline \multirow[t]{2}{*}{ Species } & \multirow{2}{*}{$\begin{array}{l}\text { Interaction } p \text { value } \\
\text { MPA } * \text { size class }\end{array}$} & \multirow{2}{*}{$\begin{array}{l}\text { Main effects } p \text { value } \\
\text { MPA and non-MPA }\end{array}$} & \multicolumn{2}{|c|}{$\begin{array}{l}\text { Mean count of fish (per } \\
\text { site per transect) }\end{array}$} \\
\hline & & & MPA & Non-MPA \\
\hline A. rogaa & 0.01 & 0.05 & 0.70 & 0.39 \\
\hline C. nigripinnis & 0.03 & 0.31 & 0.25 & 0.14 \\
\hline E. fasciatus & 0.54 & 0.42 & 0.25 & 0.22 \\
\hline C. miniata & 0.41 & 0.05 & 0.62 & 0.15 \\
\hline C. argus & 0.70 & 0.16 & 0.91 & 0.43 \\
\hline A. leucogrammicus & 0.41 & 0.04 & 0.44 & 0.18 \\
\hline
\end{tabular}

2.2.2. Coral. Line Intercept Transect (LIT) surveys took place in the six-month survey period of January-June 2012. The same sites were used as for the fish surveys (Figure 1), with six transects per site. $10 \mathrm{~m}$ tapes were used, with all benthic composition and substrates under the tape being recorded to the nearest $\mathrm{cm}$. Corals were recorded to genus level, and all coral colony structure types were documented. Tapes were placed in line with the reef parallel to the shore line.

\subsection{Data Analysis}

2.3.1. Groupers. A generalised linear mixed model (GLMM) was used to determine differences in factors of interest for each of the six grouper species in turn. We considered two fixed factors (MPA, whether there was a difference in the number of grouper inside MPAs or outside it) and size class (whether there were more grouper in certain size classes). We also considered the interaction of these terms (whether there were more grouper of only certain size classes in the MPA compared to outside). Exploratory plots of count of grouper per site showed that there were consistent patterns over time, with some sites having more grouper than others. To account for the repeated sampling at the same site, site was included as a random factor in the mixed model and was nested in the MPA term.

Since count data were used, a Poisson link function was used as part of the glmer function in the lme 4 package in $\mathrm{R}$ [51]. Given the difficulties of calculating $p$ values for GLMM, to determine significance of the interaction term, we compared the full model with interactions to the full model with just the main effects (with random structures identical in both cases) and tested for significant differences in explanatory power between the two models using the ANOVA function. Following recommendations in Underwood [52], we only tested for significance of main effects if interaction terms were not significant. In this case, to determine differences in the count of fish between MPA site and non-MPA site, we reduced the main effects model (excluding the interaction term) to exclude MPA as a main effect, and compared it to the model which included it as a main effect, using ANOVA.

An analysis was also performed to see if the effect of protection varied between the two protected areas. The same analysis was used as above, however, this time with a subset of the data (removing all those from outside MPAs), and

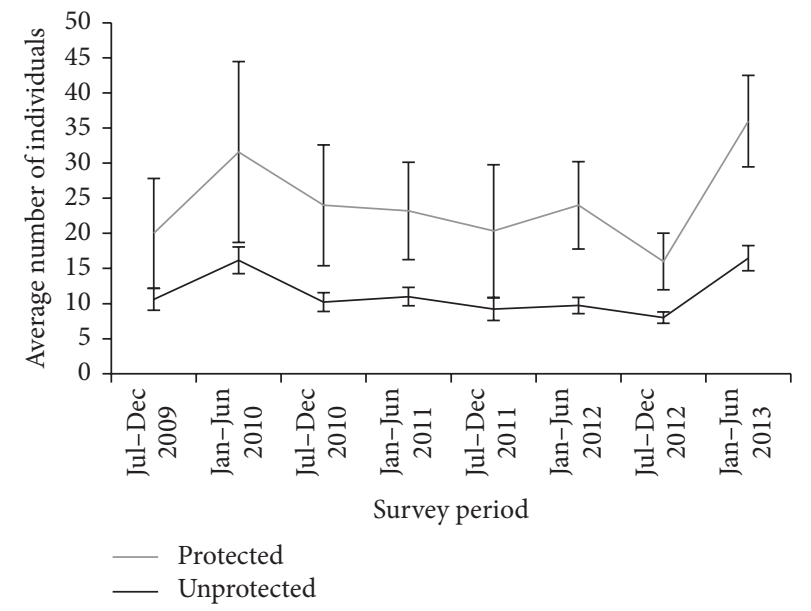

FIGURE 2: Mean abundance (SE \pm ) of all grouper species from 2009 to 2013 .

recoding of the factor MPA to indicate the two different protected areas, rather than protected or unprotected, as used previously.

2.3.2. Coral. All transect results were totaled for each site in order to compare coral diversity, amount of live coral cover, and the presence of various coral colony structure types between sites.

\section{Results}

On average and throughout the survey period, MPAs held higher counts of fish than unprotected sites (Figure 2). However, there was also high variation observed on protected sites.

There was a significant interaction of size category and MPA for $A$. rogaa and $C$. nigripinnis, meaning that the presence of protected sites had proportionally different effects on the abundance of each species, depending on which size category the individuals were in (Table 1 and Figure 3). By examining mean counts for size classes for MPA and nonMPAs (average counts of all fish, for all sites for all survey periods), we can see that there is a large increase in the counts for the small/medium size class $(11-20 \mathrm{~cm})$ within MPAs for 

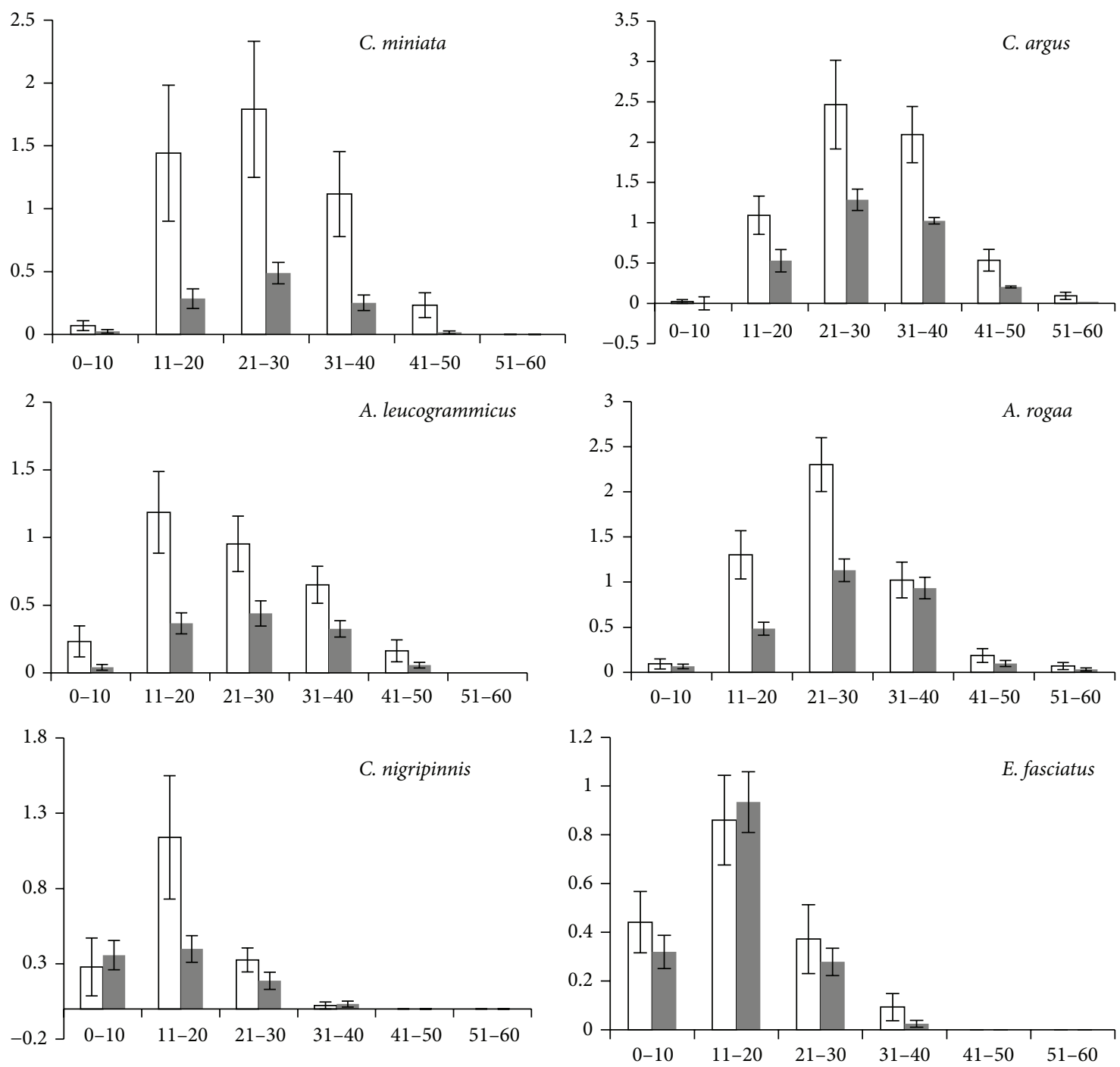

Figure 3: Mean $( \pm$ SE) count per sample at each size category. Dark bars = over all sites sampled outside of MPA; light bars = over all sites sampled inside of MPA.

C. nigripinnis (Figure 3). For A. rogaa, the interaction also likely arises from increases to the small and median size classes (11-20 and 21-30 cm) (Figure 3). While there was no significant interaction term for A. leucogrammicus, there were significantly more individuals of this species within MPAs than outside, but the difference was consistent over size classes (Figure 3).

There was no significant interaction or difference between sites located within MPAs and outside MPAs for C. miniata and $C$. argus, even though mean values were consistently higher across the size classes for fish in the MPA (Figure 3), indicating that there was high variation between sites within the data set. E. fasciatus showed no significant differences, nor were consistent differences graphically visible (Figure 3).

Assessment between MPAs showed significantly more fish were found for most species within BTMNP than PLMNP. No significant interaction terms were found for any species, meaning that fish sizes were distributed in a similar manner at both MPAs (Table 2). There was no significant difference in the mean counts of fish between the two MPAs for A. leucogrammicus and E. fasciatus.

As there was high variation observed between sites for different species, this was broken down to look at in further detail to see if there were any patterns regarding site occupation. Counts for all survey periods were summarised per species per site, with dark bars indicating protected sites (Figure 4).

For all species excluding E. fasciatus and C. nigripinnis, site BTC situated in the centre of the BTMNP showed the highest mean counts of groupers across years (Figure 4). The highest average counts of $C$. nigripinnis were found at the shallow carbonate protected sites of SB and BTNW within BTMNP; however, large values for standard error at SB indicate high variation in counts between survey periods 
TABLE 2: Results of mixed model analysis on the interaction between size category and the count of grouper species between the two MPAs. Where no significant interaction term was found, the main effect of MPA was examined.

\begin{tabular}{lccc}
\hline Species & Interaction $p$ value & ANOVA total fish & \multicolumn{2}{c}{$\begin{array}{c}\text { Mean count of fish (per } \\
\text { site per transect) } \\
\text { BTMNP * PLMNP }\end{array}$} & BTMNP * PLMNP & $\mathbf{0 . 0 2}$ & 0.30 \\
\hline A. rogaa & 0.28 & 0.01 & 0.02 \\
C. nigripinnis & 0.96 & 0.99 & 0.25 \\
E. fasciatus & 0.25 & $\mathbf{0 . 0 3}$ & 0.06 \\
C. miniata & 0.89 & $\mathbf{0 . 0 1}$ & 0.19 \\
C. argus & 0.98 & 0.08 & 0.38 \\
A. leucogrammicus & 0.91 & 0.18 & 0.91 \\
\hline
\end{tabular}

(average $=0.57, \mathrm{SE}=0.43$ ). E. fasciatus appeared fairly spread across sites. The species with the highest site selectivity was $C$. miniata, with the sites of BTC and BTNE within the BTMNP being the most prominent and low counts for all other sites.

Assessment of coral colony structure types showed the dominant structure type for both protected and unprotected sites were branching corals (Figure 5). Encrusting, massive, and submassive structure types also contributed to the reef with mushroom and foliose forms being found in relatively low abundance. Not only were branching corals the dominant structure type for both categories, but also they were comparatively higher for protected sites (Figure 5). This was tested to see if it was significant. Exploratory analysis showed a skewed distribution for protected sites; therefore, a Mann-Whitney $U$ test was used. Protected sites showed a significantly higher coverage of branching coral (Mann-Whitney $U: 11, N_{1}: 16$, $N_{2}: 6$, and $\left.p: 0.005\right)$. In terms of specific sites, BTC had the highest proportion of branching corals by a considerable margin (percentage coverage of branching corals at BTC = $37.27 \%$, average for all other sites combined $=13.75 \%, \mathrm{SD} \pm$ 5.57).

Protected sites on average had a greater coverage of live coral (mean coral cover for protected sites $43.58 \%$, SD \pm 7.4, mean coral cover unprotected sites $36.83 \%$, SD \pm 7.1 ). Breaking down the coral analysis to the site level, we found that the two protected sites of Baie Ternay Centre and Port Launay West Rocks had the greatest coverage of live coral. While the two sites with the highest values for coral genera diversity were the two protected sites of BTC and Port Launay South Reef, the mean overall coral genera diversity was similar between protected and unprotected sites (mean coral diversity protected sites $32.67 \mathrm{SD} \pm 3.5$, mean coral diversity unprotected sites $31.2, \mathrm{SD} \pm 3.1$ ).

\section{Discussion}

Our results found a significant interaction between size distribution and MPA for two species: C. nigripinnis and A. rogaa. Similar but nonsignificant trends were found for a further two species, and for A. leucogrammicus the abundance was higher in protected areas, regardless of size category. While our results were consistent with many other studies [8, 16-19] that MPAs typically hold higher densities of fish (indicated by higher average counts), our mean counts of fish indicate that for those species with a significant interaction term this is likely due to higher counts of small and medium sized fish rather than an increase in the presence of larger fish.

Firstly, it appears that our data are consistent with previous studies that these two MPAs are likely too small to sufficiently cover the home ranges of larger groupers and that bigger groupers probably move outside of the MPA more regularly and therefore are less likely to be counted. This fits with Popple and Hunte [53] who estimated through the use of acoustic tagging that the home range sizes of relatively small individuals of the species Cephalopholis cruentata were between 1.2 and $4 \mathrm{~km}$. A study by Sluka and Reichenbach [54] found that $A$. rogaa and A. leucogrammicus had more variable distribution patterns than other grouper species, suggesting either less territoriality or larger home ranges. This is logical as these two species reach the largest maximum sizes of groupers covered in this study [55] and therefore would likely require larger home ranges.

A study by Shpigel and Fishelson however [49] found that $C$. miniata and $C$. argus had relatively small home ranges $\left(475 \mathrm{~m}^{2}\right.$ and $2000 \mathrm{~m}^{2}$, resp.). However, the study also identified behavioural aspects and highlighted some features that may affect adult grouper occupation of sites. They found that C. miniata and C. argus formed multifaceted haremic home ranges that were subdivided into territories occupied by individual females. This social structure would have a limiting effect on the number of adult individuals that could occupy any given area; therefore, there may be such a thing as a social carrying capacity. The study also found a dominance hierarchy between grouper species, indicating that both inter- and intraspecies competition occurs which could potentially be a further limiting factor for the occupation of adult groupers. Intraspecies competition could explain the distribution patterns observed for E. fasciatus, as there was no interaction between size classes, similar mean counts between protected and unprotected areas, and no obvious strong favouritism for particular sites. As this is one of the smallest of our grouper species, it is highly likely that this species is less dominant in the hierarchal competitive scale and therefore is forced to be more of a habitat generalist. It is frequently seen resting in open rocky areas and is not commonly seen in areas of dense coral cover, suggesting adaptations towards this environment. 

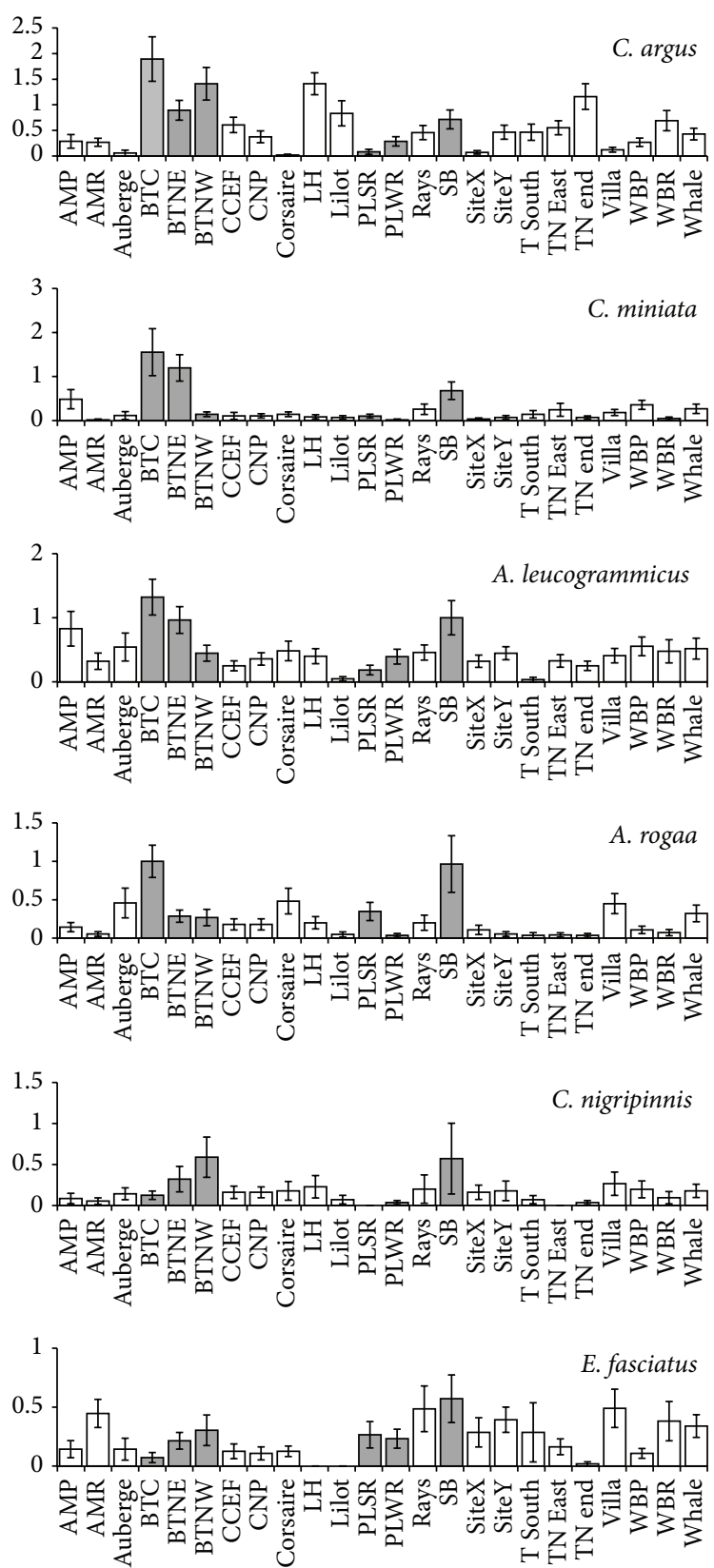

FIGURE 4: Mean counts of fish per survey site summarised over all years. Sites are listed alphabetically from left to right; dark bars indicate sites within MPAs.

Another explanation for why higher numbers of larger groupers were not found within MPA sites may be the fact that larger groupers simply are not present within the areas that were surveyed. Studies by Sluka [56] and Tupper [57] have shown that groupers go through ontogenetic habitat shifts throughout their life. As the fish matures, changes to body size mean that priorities shift from hiding from predators to its ability to predate. As mentioned in Section 2.1, surveys were only conducted to a maximum depth of $16 \mathrm{~m}$. Studies by Beaumariage and Bullock [58] and Stewart [59] found that larger groupers likely move into deeper waters,

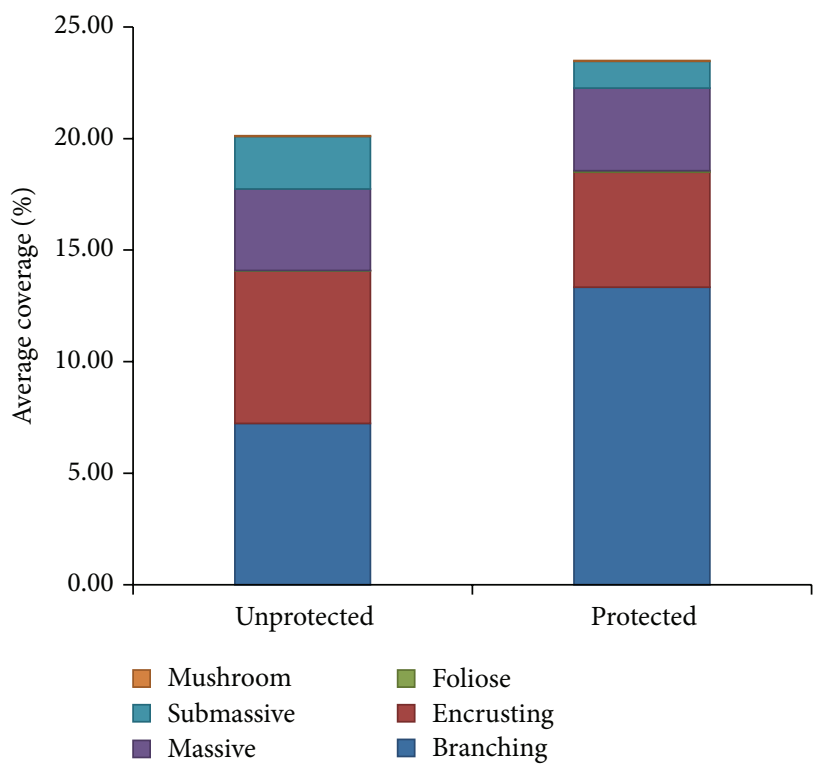

Figure 5: Average amount of coral structure types recorded on protected and unprotected sites in terms of percentages.

meaning that these individuals may have moved out of our survey range. As the two MPAs are situated within bays, it is likely that these deeper sites fall outside of MPAs. This could highlight an issue mentioned in Unsworth et al. [60] that MPAs do not always cover the full range of habitats required by species throughout their life cycle.

Interestingly, the LIT data showed that BTC and Port Launay SR had the greatest diversity in coral genera. Due to the adjacent hotel and increased anthropogenic activity, it would be assumed that this would create more challenging conditions for coral and should result in lower diversity, excluding the more sensitive corals. However, this does not appear to be the case, with the other site within the PLMNP also showing median values for coral diversity. Even though coral diversity was fairly high there were low counts for all grouper species at this site, indicating that coral diversity is not the primary factor for groupers. Similarly, Port Launay WR also had one of the highest values of live coral cover yet also had fairly low average counts. It is unsurprising that BTC, with both high coral diversity and large amounts of live coral cover and branching colonies, was the site with the highest average counts for most grouper species. This indicates that reef quality is important for grouper occupation; however, simply having high diversity or live coral coverage alone is not enough. Interestingly, the two species which did not show BTC with the highest average counts were the two smallest species, C. nigripinnis and E. fasciatus, further suggesting that intraspecies competition occurs. It is likely that the increased structural complexity from the high abundance of branching colonies at BTC is an important factor in the higher average counts of grouper at this site. Greater structural complexity would provide more areas for cover for juvenile groupers, possibly explaining why a greater count of smaller fish was found within MPAs for some species [33]. A study by 
Snyder et al. [61] argues that A. rogaa has both physical and behavioural adaptations to its juvenile stage that allow it to be a more efficient reef hunter. As the fish that they claim it mimics (small dark angelfishes of the genus Centropyge) are associated with areas of high coral cover [29], these areas would provide not only better areas to hide from predation but also better hunting grounds also. The slender grouper has also been suggested to mimic nonpredatory species during its juvenile stage [62]; however, the visual similarity with the wrasse Halichoeres purpurascens that the authors claim it mimics is more tenuous.

There are numerous studies that have found intricate relationships between coral health and the fish communities associated with it; therefore, it is not surprising that the same can be said for grouper species, especially at their younger stages when they are more vulnerable. However, patterns in occupation were not just found for smaller groupers. While there was no size interaction for A. leucogrammicus, the fact that it had significantly higher counts within MPAs than outside indicates that coral quality can be an important factor for some species throughout its life cycle. Annual reports from GVI indicate that coral recovery has been faster within MPAs than outside [63], thereby indicating that protection is having indirect effects on groupers through habitat preservation.

\section{Conclusion and Management Implications}

The study supports previous research that reserve size should be matched to the desired species. However, the authors also acknowledge that most MPAs are not typically designated for individual species, are typically multiuse, and that it is not always practical to designate large areas. The fact that even small MPAs can protect some life history stages for some species adds to the rationale for MPA establishment and can factor into identifying future protected zones within Marine Spatial Planning frameworks. While it is an ideal scenario to design MPAs to be the most effective, the results of this study show that the protection afforded to habitat by the MPAs is undoubtedly a key factor in providing better areas for foraging and refuge. The results in this study also support other studies that habitat quality like coral coverage and structural complexity are important factors for groupers, and the coral LIT data show that the MPAs in our study typically have better coral coverage. This study shows that MPAs can be an effective conservation tool for groupers; however, this is primarily through improvements to habitat and structural complexity which benefits groupers mostly at their smaller stages. The MPAs are not likely to benefit larger groupers, and indeed do not appear to sufficiently cover the habitats they require, so it is likely that larger groupers leave the MPAs or are found at depths below those surveyed for this study. However, as reef quality is typically better within MPAs and this benefits younger groupers, then the MPAs do help through facilitating recruitment to the population. However, the lack of quality habitat surrounding the MPAs likely diminishes any benefits that could be seen through spill-over.
By comparing species within a family, the results in this study highlight the varied responses within a taxonomic family to protection that may be overlooked when assessing effectiveness of MPAs at the family level. The results highlight the need for future studies to explore grouper ecology and improve our understanding of how groupers utilise different habitats, especially throughout their life cycle. Further studies on grouper distribution within larger MPAs would help to test whether some of the assumptions of this study are true.

\section{Competing Interests}

The authors declare that they have no competing interests.

\section{References}

[1] S. E. Lester, B. S. Halpern, K. Grorud-Colvert et al., "Biological effects within no-take marine reserves: a global synthesis," Marine Ecology Progress Series, vol. 384, no. 2, pp. 33-46, 2009.

[2] S. Perera-Valderrama, H. Hernández-Arana, M. Ruiz-Zárate et al., "Condition assessment of coral reefs of two marine protected areas under different regimes of use in the northwestern Caribbean," Ocean \& Coastal Management, vol. 127, pp. 16-25, 2016.

[3] J. E. Watson, E. S. Darling, O. Venter et al., "Bolder science needed now for protected areas," Conservation Biology, vol. 30, no. 2, pp. 243-248, 2016.

[4] C. K. Whitney, J. Gardner, N. C. Ban, C. Vis, S. Quon, and S. Dionne, "Imprecise and weakly assessed: evaluating voluntary measures for management of marine protected areas," Marine Policy, vol. 69, pp. 92-101, 2016.

[5] F. R. Gell and C. M. Roberts, "Benefits beyond boundaries: the fishery effects of marine reserves," Trends in Ecology and Evolution, vol. 18, no. 9, pp. 448-455, 2003.

[6] T. R. McClanahan, N. A. J. Graham, J. M. Calnan, and M. A. MacNeil, "Toward pristine biomass: reef fish recovery in coral reef marine protected areas in Kenya," Ecological Applications, vol. 17, no. 4, pp. 1055-1067, 2007.

[7] T. R. McClanahan and A. T. Humphries, "Differential and slow life-history responses of fishes to coral reef closures," Marine Ecology Progress Series, vol. 469, pp. 121-131, 2012.

[8] G. R. Russ, K. I. Miller, J. R. Rizzari, and A. C. Alcala, "Longterm no-take marine reserve and benthic habitat effects on coral reef fishes," Marine Ecology Progress Series, vol. 529, pp. 233-248, 2015.

[9] R. A. Abesamis, A. L. Green, G. R. Russ, and C. R. L. Jadloc, "The intrinsic vulnerability to fishing of coral reef fishes and their differential recovery in fishery closures," Reviews in Fish Biology and Fisheries, vol. 24, no. 4, pp. 1033-1063, 2014.

[10] D. Mateos-Molina, M. T. Schärer-Umpierre, R. S. Appeldoorn, and J. A. García-Charton, "Measuring the effectiveness of a Caribbean oceanic island no-take zone with an asymmetrical BACI approach," Fisheries Research, vol. 150, pp. 1-10, 2014.

[11] T. R. McClanahan, "Recovery of functional groups and trophic relationships in tropical fisheries closures," Marine Ecology Progress Series, vol. 497, pp. 13-23, 2014.

[12] R. A. Abesamis, G. R. Russ, and A. C. Alcala, "Gradients of abundance of fish across no-take marine reserve boundaries: evidence from Philippine coral reefs," Aquatic Conservation: Marine and Freshwater Ecosystems, vol. 16, no. 4, pp. 349-371, 2006. 
[13] L. W. Botsford, J. W. White, M.-A. Coffroth et al., "Connectivity and resilience of coral reef metapopulations in marine protected areas: matching empirical efforts to predictive needs," Coral Reefs, vol. 28, no. 2, pp. 327-337, 2009.

[14] M. L. Berumen, G. R. Almany, S. Planes, G. P. Jones, P. SaenzAgudelo, and S. R. Thorrold, "Persistence of self-recruitment and patterns of larval connectivity in a marine protected area network," Ecology and Evolution, vol. 2, no. 2, pp. 444-452, 2012.

[15] H. B. Harrison, D. H. Williamson, R. D. Evans et al., "Larval export from marine reserves and the recruitment benefit for fish and fisheries," Current Biology, vol. 22, no. 11, pp. 1023-1028, 2012.

[16] A. C. Alcala, G. R. Russ, A. P. Maypa, and H. P. Calumpong, "A long-term, spatially replicated experimental test of the effect of marine reserves on local fish yields," Canadian Journal of Fisheries and Aquatic Sciences, vol. 62, no. 1, pp. 98-108, 2005.

[17] S. D. Gaines, C. White, M. H. Carr, and S. R. Palumbi, "Designing marine reserve networks for both conservation and fisheries management," Proceedings of the National Academy of Sciences of the United States of America, vol. 107, no. 43, pp. 18286-18293, 2010.

[18] B. M. Fitzpatrick, E. S. Harvey, T. J. Langlois, R. Babcock, and E. Twiggs, "Effects of fishing on fish assemblages at the reefscape scale," Marine Ecology Progress Series, vol. 524, pp. 241-253, 2015.

[19] R. C. Babcock, N. T. Shears, A. C. Alcala et al., "Decadal trends in marine reserves reveal differential rates of change in direct and indirect effects," Proceedings of the National Academy of Sciences of the United States of America, vol. 107, no. 43, pp. 18256-18261, 2010.

[20] T. Agardy, G. N. di Sciara, and P. Christie, "Mind the gap: addressing the shortcomings of marine protected areas through large scale marine spatial planning," Marine Policy, vol. 35, no. 2, pp. 226-232, 2011.

[21] A. N. H. Smith, M. J. Anderson, R. B. Millar, and T. J. Willis, "Effects of marine reserves in the context of spatial and temporal variation: an analysis using Bayesian zero-inflated mixed models," Marine Ecology Progress Series, vol. 499, pp. 203-216, 2014.

[22] P. J. Ferraro and R. L. Pressey, "Measuring the difference made by conservation initiatives: protected areas and their environmental and social impacts," Philosophical Transactions of the Royal Society B: Biological Sciences, vol. 370, no. 1681, 2015.

[23] T. P. Hughes, "Catastrophes, phase shifts, and large-scale degradation of a Caribbean coral reef," Science, vol. 265, no. 5178, pp. 1547-1551, 1994.

[24] M. Scheffer, S. Carpenter, J. A. Foley, C. Folke, and B. Walker, "Catastrophic shifts in ecosystems," Nature, vol. 413, no. 6856, pp. 591-596, 2001.

[25] D. R. Bellwood, T. P. Hughes, C. Folke, and M. Nyström, "Confronting the coral reef crisis," Nature, vol. 429, no. 6994, pp. 827-833, 2004.

[26] A. V. Norström, M. Nyström, J. Lokrantz, and C. Folke, "Alternative states on coral reefs: beyond coral-macroalgal phase shifts," Marine Ecology Progress Series, vol. 376, pp. 295-306, 2009.

[27] P. J. Mumby, A. R. Harborne, J. Williams et al., “Trophic cascade facilitates coral recruitment in a marine reserve," Proceedings of the National Academy of Sciences of the United States of America, vol. 104, no. 20, pp. 8362-8367, 2007.

[28] M. L. Baskett and L. A. K. Barnett, "The ecological and evolutionary consequences of marine reserves," Annual Review of Ecology, Evolution, and Systematics, vol. 46, pp. 49-73, 2015.
[29] J. D. Bell and R. Galzin, "Influence of live coral cover on coralreef fish communities," Marine Ecology Progress Series, no. 15, pp. 265-274, 1984.

[30] P. Chabanet, H. Ralambondrainy, M. Amanieu, G. Faure, and R. Galzin, "Relationships between coral reef substrata and fish," Coral Reefs, vol. 16, no. 2, pp. 93-102, 1997.

[31] J. S. Beukers and G. P. Jones, "Habitat complexity modifies the impact of piscivores on a coral reef fish population," Oecologia, vol. 114, no. 1, pp. 50-59, 1998.

[32] S. K. Wilson, S. C. Burgess, A. J. Cheal et al., "Habitat utilization by coral reef fish: implications for specialists vs. generalists in a changing environment," Journal of Animal Ecology, vol. 77, no. 2, pp. 220-228, 2008.

[33] N. A. J. Graham and K. L. Nash, "The importance of structural complexity in coral reef ecosystems," Coral Reefs, vol. 32, no. 2, pp. 315-326, 2013.

[34] M. C. Öhman and A. Rajasuriya, "Relationships between habitat structure and fish communities on coral," Environmental Biology of Fishes, vol. 53, no. 1, pp. 19-31, 1998.

[35] G. R. Almany, "Does increased habitat complexity reduce predation and competition in coral reef fish assemblages?" Oikos, vol. 106, no. 2, pp. 275-284, 2004.

[36] M. A. Hixon and M. H. Carr, "Synergistic predation, density dependence, and population regulation in marine fish," Science, vol. 277, no. 5328, pp. 946-949, 1997.

[37] M. A. Hixon and J. P. Beets, "Predation, prey refuges, and the structure of coral-reef fish assemblages," Ecological Monographs, vol. 63, no. 1, pp. 77-101, 1993.

[38] J. A. Dunne, R. J. Williams, and N. D. Martinez, "Network structure and biodiversity loss in food webs: robustness increases with connectance," Ecology Letters, vol. 5, no. 4, pp. 558-567, 2002.

[39] G. D. Grimsditch and R. V. Salm, Coral Reef Resilience and Resistance to Bleaching, IUCN, Gland, Switzerland, 2006.

[40] W. Fischer, I. Sousa, C. Silva et al., Fichas FAO de Identificaçao de Espécies para Actividades de Pesca. Guia de Campo das Espécies Comerciais Marinhas e de Águas Salobras de Moçambique. Publicaçao Preparada em Collaboraçao com o Instituto de Investigaçao Pesquiera de Moçambique, com financiamento do Projecto PNUD/FAO MOZ/86/030 e de NORAD, FAO, Roma, Italy, 1990.

[41] G. R. Allen, M. V. Erdmann, D. R. Robertson et al., Reef Fishes of the East Indies, vol. 1, 2012.

[42] Y. Sadovy de Mitcheson, M. T. Craig, A. A. Bertoncini et al., "Fishing groupers towards extinction: a global assessment of threats and extinction risks in a billion dollar fishery," Fish and Fisheries, vol. 14, no. 2, pp. 119-136, 2013.

[43] M. D. Spalding and G. E. Jarvis, "The impact of the 1998 coral mortality on reef fish communities in the Seychelles," Marine Pollution Bulletin, vol. 44, no. 4, pp. 309-321, 2002.

[44] N. A. J. Graham, S. K. Wilson, S. Jennings et al., "Lag effects in the impacts of mass coral bleaching on coral reef fish, fisheries, and ecosystems," Conservation Biology, vol. 21, no. 5, pp. 12911300, 2007.

[45] T. Spencer, K. A. Teleki, C. Bradshaw, and M. D. Spalding, "Coral bleaching in southern Seychelles," in Coral Reef Degradation in the Indian Ocean, D. Souter, D. Obura, and O. Linden, Eds., pp. 87-93, CORDIO, Stockholm, Sweden, 2000.

[46] Ministry of Environment \& Energy Seychelles' Protected Areas Policy, 2013, http://www.gov.sc/edoc/pubs/frmpubdetail.aspx? pubId $=25$. 
[47] National Parks and Nature Conservancy Act, 1991, http://www .seylii.org/sc/legislation/consolidated-act/141.

[48] U. Engelhardt, Interim Report No. 1 (December 2001): Report on Scientific Field Studies and Training Activities Conducted in June/July 2001. Seychelles Marine Ecosystem Management Project, Reefcare International, Townsville, Australia, 2001.

[49] M. Shpigel and L. Fishelson, "Territoriality and associated behaviour in three species of the genus Cephalopholis (Pisces: Serranidae) in the Gulf of Aqaba, Red Sea," Journal of Fish Biology, vol. 38, no. 6, pp. 887-896, 1991.

[50] J. Bijoux, Personal Communication, Seychelles Fishing Authority, 2015.

[51] D. Bates, M. Mächler, B. M. Bolker, and S. C. Walker, "Fitting linear mixed-effects models using lme4," Journal of Statistical Software, vol. 67, no. 1, pp. 1-48, 2015.

[52] A. J. Underwood, Experiments in Ecology: Their Logical Design and Interpretation Using Analysis of Variance, Cambridge University Press, 1997.

[53] I. D. Popple and W. Hunte, "Movement patterns of Cephalopholis cruentata in a marine reserve in St Lucia, W.I., obtained from ultrasonic telemetry," Journal of Fish Biology, vol. 67, no. 4, pp. 981-992, 2005.

[54] R. D. Sluka and N. Reichenbach, "Grouper density and diversity at two sites in the Republic of Maldives," Atoll Research Bulletin, no. 438, pp. 1-16, 1995.

[55] G. R. Allen and M. V. Erdmann, Reef Fishes of the East Indies, vol. 1, University of Hawai'i Press, 2012.

[56] R. D. Sluka, "Grouper and napoleon wrasse ecology in Laamu atoll, republic of Maldives: part 1. Habitat, behavior, and movement patterns," Atoll Research Bulletin, vol. 491, pp. 1-26, 2000.

[57] M. Tupper, "Identification of nursery habitats for commercially valuable humphead wrasse Cheilinus undulatus and large groupers (Pisces: Serranidae) in Palau," Marine Ecology Progress Series, vol. 332, pp. 189-199, 2007.

[58] D. S. Beaumariage and L. H. Bullock, Biological Research on Snappers and Groupers as Related to Fishery Management Requirements, Florida Sea Grant College Program, 1976.

[59] V. N. Stewart, Grouper. Sea-Stats No. 8, Florida Department of Natural Resources, St. Petersburg, Fla, USA, 1989.

[60] R. K. F. Unsworth, A. Powell, F. Hukom, and D. J. Smith, “The ecology of Indo-Pacific grouper (Serranidae) species and the effects of a small scale no take area on grouper assemblage, abundance and size frequency distribution," Marine Biology, vol. 152, no. 2, pp. 243-254, 2007.

[61] D. B. Snyder, J. E. Randall, and S. W. Michael, "Aggressive mimicry by the juvenile of the Redmouth Grouper, Aethaloperca rogaa (Serranidae)," Cybium, vol. 25, no. 3, pp. 227-232, 2001.

[62] P. C. Heemstra, D. Pollard, M. Samoilys, B. Yeeting, and J. H. Choat, "Anyperodon leucogrammicus," The IUCN Red List of Threatened Species, Version 2015.2, http://www.iucnredlist.org.

[63] L. Cassidy and G. Frank, GVI Seychelles Marine Report, Series No. 121, 2012. 

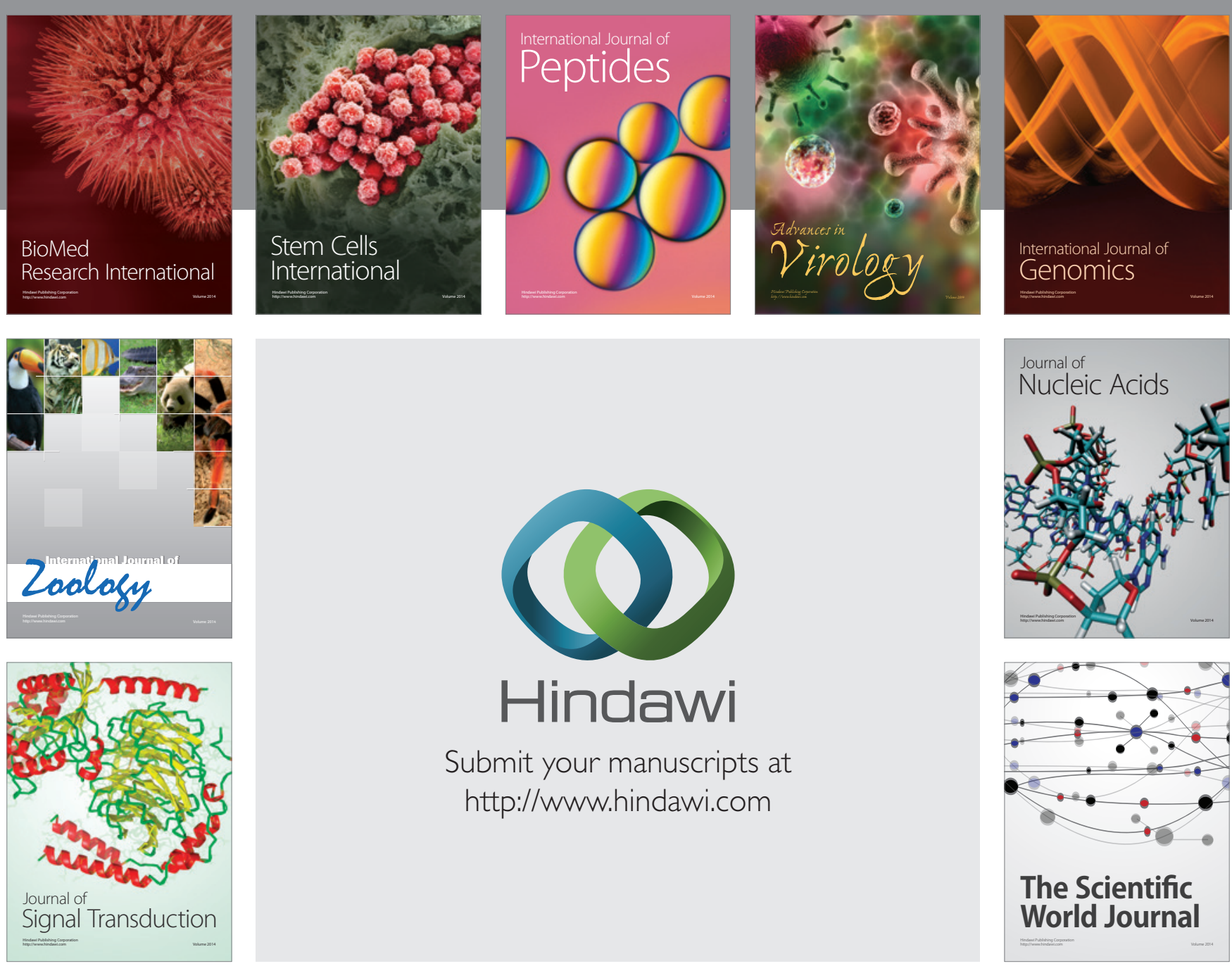

Submit your manuscripts at

http://www.hindawi.com
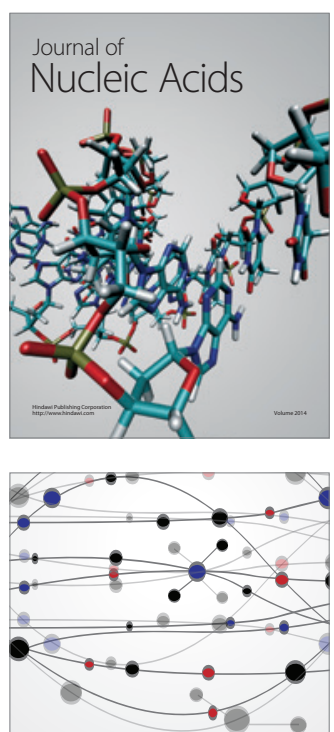

The Scientific World Journal
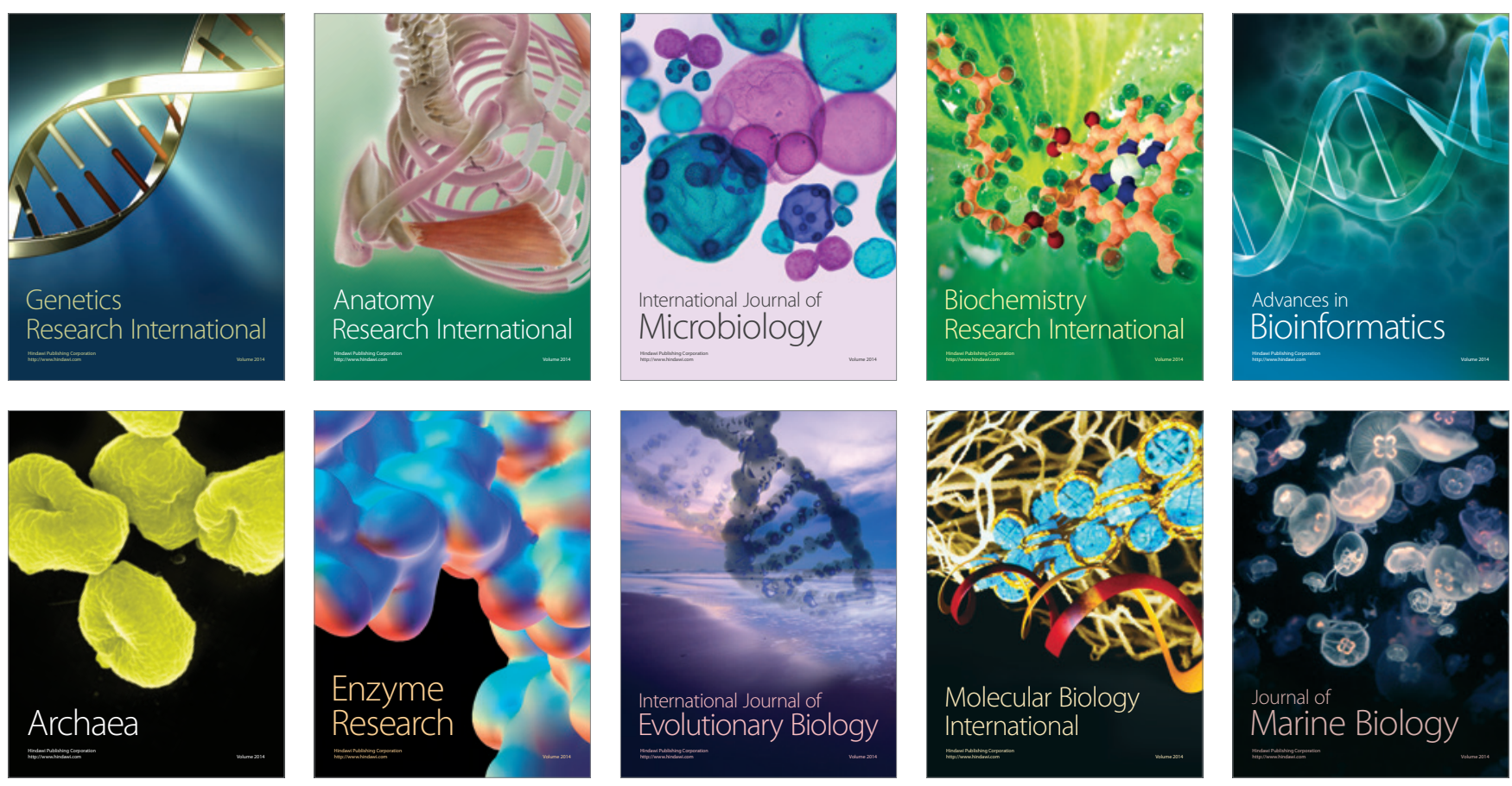